\title{
17 \\ Comparing Country Cases: Output-Oriented EU Democracy Promotion?
}

\author{
Anne Wetzel and Jan Orbie
}

\section{Introduction}

The purpose of this book has been to map and explain the substance of European Union (EU) democracy promotion. The adapted framework of embedded liberal democracy provided the analytical framework for the mapping exercise, whereas the four hypotheses guided the authors' search for explanations (see the introductory chapter). Based on our systematic and comparative analysis involving the EU's policy towards 22 countries, this concluding chapter will formulate a number of general conclusions. We find that the 'default substance' of the EU's democracy promotion is output-oriented, specifically targeting 'socio-economic development' and 'state administrative capacity'. Partial regimes, and in particular 'horizontal accountability' and 'effective power to govern', tend to be under-addressed.

However, we also find some interesting deviations from this general pattern, not least in relation to countries that are located close to the EU. The different hypotheses, and in particular the power and domestic context hypotheses, shed light on this diversity. Based on the results, the rough distinction between 'partial regimes' and 'external conditions', and the concomitant distinction between 'narrow' and 'shallow' democracy promotion (Wetzel and Orbie 2011; the introductory chapter), can also be refined.

Before elaborating on these conclusions, some methodological notes should be made on how we have come to our findings. Most importantly, we differentiate between 'absolute' and 'relative' substance. The absolute substance concerns the extent to which a specific component 
of the framework has been addressed. This is in line with the scores provided by the contributors to Table A.1 (see Annex). The shading provides an initial indication of which components and which countries have been more or less important for the EU. However, while this table provides a good overview of what has been the focus of the EU's attention, it is a purely descriptive device that tells us little about possible explanations. For example, some countries and components may receive more attention than others because domestic deficiencies are stronger (cf. the domestic context hypothesis).

Therefore, in a second step, we compared the scores of the substance table with the democratic 'deficiencies' in the third countries, which gives us an idea of the 'relative' substance, denoting the difference between the 'absolute' values in the above-mentioned substance table and the domestic situation in the third country. The differences allow us to gauge the extent to which the EU 'overperforms' or 'underperforms' in relation to domestic 'deficits', in line with the domestic context hypothesis. Specifically, we compared the available Bertelsmann Transformation Index (BTI) values for all components for the year 2006, represented in a condensed form in Table A.2, with the values of the substance table (for the original values, see BTI 2012). The original BTI values that range between 1 ('worst') and 10 ('best') were subsumed into four categories that conversely correspond to the four values in the substance tables. The BTI table thus shows where there are the biggest deficits in those countries for which values are available. ${ }^{1}$ This approach reveals that there is a clear and underlying output-oriented tendency, even if the EU does not recommend the same 'size' of this model to the different target states. The 'basso continuo' of EU democracy promotion consists of socio-economic development and state capacity.

\section{Output democracy as the default substance}

Previous research has led to the conclusion that the EU emphasizes the external context conditions more than the partial regimes (Wetzel and Orbie 2011). The cases presented in this edited volume generally confirm this pattern. In absolute terms, but also after the comparison with the 'deficiencies' in the countries, 'socio-economic development' and 'state administrative capacity' are the major focal points of the EU's international democracy promotion policy. Not only did the EU put most emphasis on these two components, but overall the EU's substance also matches most closely with the domestic deficiencies in these fields and sometimes the EU even overperforms. This close match relates to 


\section{8 \\ Comparison and Conclusion}

almost all cases (with the exception of state administrative capacity in the Solomon Islands) - that is to say, we do not see any major deviances to the positive or negative, which suggests that it is an underlying default option.

This careful attention to socio-economic development and state capacity stands out in comparison with the other components of the adapted framework of embedded liberal democracy, which the EU tends to under-address, although to widely varying degrees both with regard to differences between components and differences between countries. The two most under-addressed components are 'effective power to govern' and 'horizontal accountability', which belong to the partial regimes. While 'effective power to govern' receives the least attention also in absolute terms, the EU's attention to horizontal accountability does not actually deviate from the remaining three partial regimes in absolute terms but displays a large gap between the existing deficiencies and the degree to which the deficiencies were addressed. With the extremes on both sides - that is, best match and worst match of substance with domestic conditions - relating to the context conditions and partial regimes, respectively, the earlier finding (Wetzel and Orbie 2011) that the EU addresses the external context conditions of democracy more, and thus that the substance of EU democracy promotion tends towards the shallow side, is confirmed.

At the same time, the contributions to this volume show that this finding can be further specified. As becomes clear from the above, not all components related to the external context are central to the EU's democracy promotion. Large differences in attention can also be detected among the partial regimes. These more fine-grained conclusions result not only from the larger number of country cases and the more systematic approach, but also from the new distinction made between 'stateness' and 'state administrative capacity'. In view of the above finding that the most addressed and also most adequately addressed components are 'socio-economic development' and 'state administrative capacity' and the least addressed and also least adequately addressed component is 'effective power to govern', we conclude that the 'default substance' of EU democracy promotion can be described as 'output democracy', with a particular emphasis on effective problem solving.

With this term, we refer to the established distinction between 'input' and 'output' as the basis of democratic legitimacy (see Scharpf 1999). Given the need to legitimize policies, Scharpf presents two ways to ensure legitimacy. While input legitimacy relates to the general 


\section{PROOF}

Anne Wetzel and Jan Orbie 239

responsiveness of governing processes 'to the manifest preferences of the governed', output legitimacy ensures 'that the policies adopted will generally represent effective solutions to common problems of the governed' (Scharpf 2003). Reduced to a short formula, input legitimacy refers to 'government by the people', whereas output legitimacy resonates with 'government for the people' (Scharpf 2003). This distinction has also been taken up in work on EU democracy promotion by Tanja Börzel and her collaborators (Börzel et al. 2008, Börzel and Hackenesch 2013).

With their emphasis on performance, both 'socio-economic development' and 'state administrative capacity' clearly correspond to the notion of 'output democracy'. ' 'Effective power to govern', on the other hand, addresses the translation of the will of the electorate into policies by ensuring that it is those who are democratically elected that govern. This largely neglected component thus clearly relates to input legitimacy. Horizontal accountability, which was also neglected in relative terms, in Scharpf's account corresponds to 'output democracy', too, but to the sub-category of preventing wrongdoing (Scharpf 2003). In the case of democracy promotion this component arguably sits in between input and output legitimacy, because a strengthening of checks and balances can be assumed to contribute to enhancing responsiveness to the electorate's preferences, for instance by making the parliament a body that is able to effectively control the government. Scharpf himself admits that there may emerge a certain trade-off between checks and balances and effective problem solving. So, the sub-categories in fact address different issues. When we speak of output democracy, we refer to effective problem solving. Furthermore, speaking of an outputdemocracy agenda does not imply that the EU completely neglects input-related components and focuses exclusively on output-related components. In fact, as emphasized by Kurki (Chapter 3), no systematic conceptual model or clear ideological vision emerges from the EU's documents and practice on what democracy means. By output-democracy agenda we rather summarize a tendency in EU democracy promotion that favours performance and spans across the narrow-shallow distinction.

The findings on civil society also support our general finding about the EU's output-oriented agenda. In absolute terms, the EU devotes considerable attention to civil society across our range of cases, and only slightly less than state administrative capacity (Table A.1). However, when looking at the relative substance, the EU tends to slightly underperform, with the two exceptions of Tunisia (before the Arab 


\section{Comparison and Conclusion}

Spring) and Eritrea, where the discrepancies are quite large. It seems fair to conclude that, despite the EU's own discourse, there is room for improvement with regard to civil society support. For instance, it was pointed out that despite the official aim of empowering civil society in the Euro-Mediterranean Partnership the concrete realization of this aim was hollowed out by intergovernmental tendencies and the exclusion of a large share of civil society actors from EU support (Simon and Jünemann 2013: 82-3). More importantly, a judgment regarding 'civil society' should take into account the qualitative assessments in the chapters (see also the introductory chapter), which support the EU's output-democracy agenda. As Börzel shows, the support of civil society can go together very well with an output-oriented agenda (for evidence from the EU eastern enlargement, see Börzel 2010: 5-6). Such an approach 'places emphasis on output-oriented reform goals as well but either includes non-state actors in the implementation process to produce better policies by pooling resources and increasing acceptance or facilitates the building and strengthening of non-state organizations that will help to implement policies better' (Börzel and Hackenesch 2013: 539). As the chapters on Russia/Ukraine (Chapter 9), Bosnia and Herzegovina/Kosovo (Chapter 8), Georgia/Armenia (Chapter 10), Croatia/Turkey (Chapter 7) and Ethiopia/Eritrea (Chapter 14) show, EU civil society promotion at least partly displays an instrumental tone. In many cases, civil society organizations have been supported in order to help implement the EU's acquis, the European Development Fund or reforms more generally in the third countries. Also, in terms of topics that civil society organizations have addressed with the help of EU support, an effective problem-solving logic can be detected at least in some cases (see for example projects on environmental protection or conflict resolution). Again, this does not mean that the EU did not foster civil society's involvement with a view to the input dimension (cf. Chapter 5 on the governance approach), but it shows that the strong focus on civil society does not, as such, contradict the overall description of the EU's democracy promotion agenda as output-oriented, and that it often tends to reinforce it.

With regard to the other components, the results are not so pronounced but, overall, support the characterization of the substance of EU democracy promotion as output-oriented. Political and civil rights generally receive attention at a medium level and on average less than they should, given the local circumstances in third countries. Elections have received more attention than one might have expected based on criticisms of the EU's technocratic democracy promotion (see 
the introductory chapter), but far less than would justify speaking of an 'electoralist fallacy'. ${ }^{3}$ The largest gap emerges in the component of 'political rights'. As is the case with 'horizontal accountability', the three components also display strong deviations from an imagined 'appropriate' substance. Cases of overperformance are in sharp contrast to cases of underperformance, which suggests a higher 'volatility' for these mainly input-related components as part of democratic substance.

How can this output-democracy bias be explained? The hypotheses advanced in the introductory chapter do not fully answer this question since they serve to explain differentiation of EU policies across the countries covered in this book - as will be illustrated below. We can rely on existing literature and on evidence provided by the authors in this book to explain the output-oriented character of EU democracy promotion. First, there is the 'nature of the beast' explanation. Scharpf (1999: 12) has already asserted that 'the European polity is fundamentally different from national democracies' given its tendency towards output-oriented legitimacy. Several other scholars have depicted the EU as a regulatory, technocratic or output-oriented political system (Majone 1994, Moravcsik 2002). It has been argued that this internal configuration predisposes the EU to act accordingly in its external relations (cf. Orbie 2011, Damro 2012). In our previous study, we emphasized that ' $[\mathrm{t}] \mathrm{he}$ EU project itself has been geared towards deepening economic integration and building multi-level governance structures', which sheds light on the substance of its democracy promotion policy (Wetzel and Orbie 2011: 724). In his 'skeptical' contribution to this volume, Kochenov also emphasizes that the intra-EU and extra-EU dimensions are 'intimately interconnected'. From a law perspective, he states that democracy may be a political 'value' for the EU and its member states, but it is 'not a real principle of law' in the EU acquis. Furthermore, he argues that 'the EU, given its nature, is a very poor candidate for a standard setter not only in the field of democracy as such, but also in all the related fields, which are necessarily connected with democracy, whether we want it or not' (see Chapter 2). The 'whether we want it or not' qualification also resonates with the argument made by Kurki (Chapter 3), who emphasizes that the pragmatic approach of the EU has the effect of being market-oriented, although there is no clear and deliberate template behind it. However, the lack of such an explicit and agreed template that would possibly include more input-related elements (cf. the demand by the European Parliament to adopt a United Nations (UN) definition of democracy mentioned in the introductory chapter) forms a perfect ground for 


\section{PROOF}

democracy promotion in 'known terrain' and in a kind of 'autopilot mode' that may be adjusted under certain circumstances.

Specifically, the 'nature of the beast' explanation connects with the institutional hypothesis of the introductory chapter, although on a more fundamental explanatory level. Rather than being tied to a particular EU institution or sub-system, it refers to a general disposition of the EU, closely connected to the institutional structure of the European polity.

Second, and complementary, the EU's emphasis on output-oriented substance also stems from feasibility concerns. When the EU faces (strong) resistance from third countries, it seems to be particularly quick to revert to output-related democracy promotion through fostering socio-economic development and state administrative capacity. In this context the EU has also used the less sensitive term 'democratic governance', which includes exactly these output-related components. Eritrea would be an example: as shown by Del Biondo (Chapter 14), the EU saw no other option than engaging in technical programmes and initiatives in areas such as women's, children's and workers' rights that are seen as less threatening to the government. The EU's policies towards China, which have not been covered in this volume, may also illustrate the feasibility argument. In the late 1990s, the EU abandoned its direct focus on the political system that characterized its response to the Tiananmen Square massacre, focusing on a less confrontational approach involving cooperation in less sensitive areas such as the rule of law (e.g. training of lawyers and judges), culture and youth (Shen 2013).

This example makes it clear that it is indeed difficult to discern whether we can still speak of democracy promotion. As stated in the introductory chapter to this volume, activities labelled as democracy promotion are counted as such when they are designed to support democracy in the sense of the framework regardless of their actual effectiveness. However, it has already been pointed out elsewhere that a sole focus on the context conditions may not necessarily further democratization (Wetzel and Orbie 2012).

In our view, feasibility concerns are subordinated to the 'nature of the beast' explanation. They can be seen as complementary in the sense that they may even enhance the EU's output-related substance of democracy promotion. We conclude this from several observations. Firstly, a low willingness and ability of third countries to cooperate with external actors (as indicated by the respective BTI score; see the introductory chapter) does not translate to the same degree to a negative discrepancy between deficiencies and substance promoted, especially with regard to 
the partial regimes. While, for instance, Russia, Egypt, Eritrea, Ethiopia and Venezuela had a score of 4 (with 10 indicating highest willingness to co-operate) in 2006, discrepancies were negative but still modest in the latter two, and larger in Russia, Egypt and Eritrea (in order of deterioration). Thus it can be concluded that even in cases of reluctant third countries, the EU has some room for manoeuvre that it can choose to use or not, and that in most cases it chooses not to use it.

Secondly, while it is true that the size of negative discrepancies increases with increasing levels of authoritarianism in the five countries as measured by Freedom House's Freedom Rating for 2006, ${ }^{4}$ it cannot automatically be concluded that this necessitates a focus on output-related substance. This becomes particularly evident with regard to the differences with US democracy promotion, which is often seen as more political, even in the face of authoritarian resistance. It has long been argued that the EU, in contrast to the US, is less a political and more a 'developmental' actor (Carothers 2009). From a different perspective, Schmidt (Chapter 4) also argues that the EU is less focused on political issues of 'how authority is exercised and who is in power' (in favour of a more sociological view). As Youngs and Pishchikova conclude (2013: 14),

ensuring real democratic reform requires [...] a willingness to delve into the messy and conflicting politics of change, and address the concerns over power that divert reform momentum. The EU lags behind the United States in this area. [...] In Europe, democracy debates lack a high-politics tenor and are couched more in terms of generic identity and standards.

While we do not make the case here for more political democracy promotion, this evidence shows that unfavourable domestic conditions do not have to be answered by a purely output-oriented strategy. After all, it is at least partly the choice of the democracy supporter to opt for such a strategy among alternatives.

The third observation relates to the fact that we did not detect much reflection and discussion among EU actors involved in democracy promotion on the potential consequences of almost entirely 'outputrelated' approaches. ${ }^{5}$ We see this as evidence for routine behaviour: although they might even be contrary to the intended aim of advancing democracy in a third country, the EU conducts them as the default option, rather than completely withdrawing assistance from the country. 


\section{PROOF}

The rare instances of sanctions in cases of democratic shortcomings are an exception. The sanctions against Fiji illustrate this (see Chapter 15). However, since the mid-2000s, the EU has become less active in applying sanctions. This is not only because their impact has been questioned and because the power of traditional donors (including the EU) has declined. It also relates to the principle of ownership that is central to international engagements on aid effectiveness, including the Paris Declaration (2005) and the Accra Agenda for Action (2008), which the EU has fully supported. Developing country governments often prefer output-oriented assistance and are hesitant regarding politically intrusive policies (Del Biondo 2011: 666-7). This, in turn, resonates particularly well with the EU's default substance.

With the conclusions to this volume, we aim to arrive at a more precise understanding of what the EU promotes. Our main finding is that the EU's default policy is not just about promoting external conditions (Wetzel and Orbie 2011) and/or about neoliberal market reform (cf. Reynaert 2011), but it is specifically about promoting socioeconomic development in tandem with state administrative capacity. We have called this the output-oriented substance of EU democracy promotion. There is also a lack of reflection by the EU on the potentially positive and negative impact of supporting socio-economic development and state administrative capacity for democracies. Both the institutional nature of the $\mathrm{EU}$ and, related to this, feasibility considerations can explain these general tendencies. However, notwithstanding this general picture, there is considerable variation across the countries and over the components, which require more specific explanations.

\section{Accounting for diversity}

Despite this underlying output-oriented approach, the EU does not promote the same 'size' of this model in the different target states. Both the absolute and relative substance of EU democracy promotion policies differ across countries and regions. There are instances where socioeconomic development and state administrative capacity are promoted less (e.g. in Russia), and others where horizontal accountability and even effective power to govern are promoted more (e.g. in Turkey and Bosnia and Herzegovina) than one might expect based on the above analysis. There is also a high volatility of certain (mostly input-related) components where the EU sometimes overperforms and sometimes underperforms. This general picture corresponds with Kurki's argument 


\section{PROOF}

Anne Wetzel and Jan Orbie 245

that despite the general (neo)liberal, market-oriented 'undercurrent' of EU democracy promotion, there is a considerable degree of 'fuzziness' with regard to the meaning of 'democracy'. She argues that this fuzziness is compatible with a range of different socio-economic models that can be promoted, and points to the "possibility of a broad range of "substances" that arises from this broad conceptual basis'. Despite its downsides, the lack of a clear model also has the advantage that it allows the EU to adopt a flexible approach according to different contexts (Chapter 3).

Based on the hypotheses presented in the introductory chapter, which also informed the country chapters throughout the book, we aim to make a more systematic assessment of different explanations for the diversity in the EU's substance. The power and domestic context factors emerge as the most salient explanations, even if the institutional and inter-organizational hypotheses also explain some parts of the puzzle. As anticipated in the introductory chapter, the different factors are also interrelated.

The power hypothesis has been confirmed in two ways. On the one hand, the EU's agenda becomes shallower when the EU expects that a broader substance would damage its (perceived) security. The same is true when the difference in capabilities and/or when the (favourable) asymmetric interdependence with the third country is relatively small. This sheds light on the few cases where even socio-economic reform and state administrative capacity are not strongly pursued by the EU, even though there would have been room for improvements. Russia is the most obvious example, where the EU underperforms in terms of relative substance, even in relation to the external context conditions. Here, (perceived) energy dependence and, to a lesser extent, general security concerns have influenced the EU's agenda (in combination with the reluctance of the Russian government to accept democracy promotion measures from the outside; see Chapter 9). The situation is similar in Kazakhstan, in contrast to Kyrgyzstan, which relies more on external assistance and is less relevant with regard to EU security concerns (see Chapter 13). In the cases of Egypt and Tunisia, there is evidence that security considerations have led the EU to take a more shallow approach, although to a different degree (see Chapter 11). This resonates with the existing literature on the democracy-stability dilemma (Andrés Viñas 2009, Jünemann 2009, Powel 2009, Börzel and van Hüllen 2014). In Israel and Palestine, the security issue was found to dominate any democracy promotion efforts. This has not only led to shallow democracy promotion but also implies that all democracy 


\section{PROOF}

promotion measures have to be seen in the light of security concerns (see Chapter 12).

The opposite is true in a different set of countries. Here, on the other hand, the EU has over-addressed some components towards countries that are less powerful. This includes the component of horizontal accountability, which was on average found to be under-addressed (see above). Less powerful countries most obviously include those that are located close to the EU, and that aspire to and have a (distant) perspective of the EU membership, such as Croatia (pre-2013) and Turkey, and, to a lesser extent, Bosnia and Herzegovina and Kosovo. In these cases, the EU tends to be over-attentive. This example shows how the institutional and power hypotheses interact. When relations between the EU and the third country take place within an enlargement (institutional) framework, the EU gains considerable leverage and the power to define the agenda. Apart from the asymmetric power relationship that is inherent to the accession process and that increases the feasibility of democracy promotion policies, other factors, including constructivist dynamics, may contribute to the EU's broad agenda towards these countries. Higher expectations may be held towards countries that are considered as 'European' and want to become members of the 'European family'. It also seems plausible that the EU aims to lock in democratic commitments within the domestic system of candidate countries before admitting them. Whatever the exact dynamics, it is clear that these countries are of a higher importance to the EU than further-away countries. This resonates with Börzel's finding that ' $[\mathrm{t}]$ he closer a candidate country moves towards accession, the more the EU shifts from the effective government to the democratic government approach' (2009: 36). It should, however, be noted that in these cases the substance is also inspired by the standards of other organizations such as the Council of Europe, the UN and the Organisation for Economic Co-operation and Development (in the cases of the Czech Republic and Slovakia, see Chapter 6), the International Criminal Tribunal for the Former Yugoslavia (ICTY), the Organization for Security and Co-operation in Europe (OSCE) (in the case of Croatia, see Chapter 7) and even the International Monetary Fund (see Chapter 7). Thus, while the EU provided the power in terms of leverage, these organizations often shaped the substance by providing expertise and legitimacy (Skovgaard 2011). In this sense, inter-organizational context was relevant in these cases.

However, the EU becomes much less ambitious towards countries that are further away, even if it is clearly in a dominant position. In this regard, the power hypothesis has to be qualified. In general, the 


\section{PROOF}

Anne Wetzel and Jan Orbie 247

EU has under-addressed partial regimes in countries outside the EU neighbourhood. In Fiji and the Solomon Islands, for instance, the EU is clearly more powerful and at the same time there are no (perceptions of) security threats. Still, the EU generally underperforms in these cases, even in the external context conditions, including state capacity, albeit with the exception of elections in the case of Fiji. A similar picture emerges for Venezuela. This indicates that a powerful position and the absence of security concerns do not automatically translate to the promotion of a broad substance.

The case of Fiji also illustrates how the power hypothesis and the inter-organizational hypothesis interrelate. The atypical substance promoted towards Fiji - that is to say, significant attention given to elections, combined with neglect of other components - can be explained because the EU has been following the regional hegemony of Australia and New Zealand (and by extension the Pacific Island Forum; see Chapter 15). The relatively broad substance towards Kyrgyzstan can be explained not only by the high asymmetrical interdependence and the comparatively low security interests (power hypothesis), but also by the relative openness of the country's government (see Chapter 13).

This leads us to elaborate on the two forms of the domestic context hypothesis, namely, the assumptions that the substance corresponds to the existing democratic deficiencies within the third country or is adjusted to governments' agendas, respectively. At first sight its explanatory value with regard to the former reading seems limited: there are significant divergences between the 'absolute' and 'relative' substance promoted by the EU (see Tables A.1 and A.2). The EU's underlying or 'default' output orientation and other factors seem more important than domestic deficiencies in terms of explaining the EU's substance. However, this should also be nuanced. All of the chapters provide evidence that the EU takes the domestic context into consideration at least to some extent, even if this does not always radically change the big picture. Moreover, the EU's tendency to emphasize socio-economic development and state administrative capacity is often in line with the domestic situation and with preferences of the ruling government (see above). Finally, there are instances where the EU has overall adequately addressed domestic deficiencies, such as in Kyrgyzstan, Ukraine and Brazil, or has responded to specific problems, such as in Kosovo and Bosnia and Herzegovina. Explanations for the EU's policy towards Kyrgyzstan have already been touched upon. In the case of Ukraine, Stewart shows how the EU has responded to the deterioration of democracy under former President Yanukovych (see Chapter 9). In Kosovo 


\section{PROOF}

and Bosnia and Herzegovina, the EU paid attention to minority rights and constitutional issues, respectively. In the latter case, the EU also responded to the hardships of the 2008/09 financial and economic crisis by increasing funds from its Instrument for Pre-Accession Assistance (IPA). Overall, the EU was found to take into account that both countries are post-conflict societies (see Chapter 8).

The case of Brazil is particular, because the two readings of the domestic hypothesis are congruent and are at the same time interconnected with the power hypothesis. As Ribeiro-Hoffmann argues, the EU's responsiveness to the Brazilian domestic context, understood as the preferences of the government, relates to the EU's desire to counterbalance US hegemony. This has led the EU to be more lenient towards the domestic government's preferences (see Chapter 16). In turn, accommodating the Brazilian government's preferences is congruent with addressing 'objective' deficiencies that mainly relate to the socio-economic situation (Table A.2). There was a high level of consensus between both partners on the necessary areas for reform, which with a view to socioeconomic development resonates well with the EU's default substance (see above). However, as other cases show, accommodating the preferences of the third country government does not necessarily mean that domestic deficiencies will be taken into account. For instance, the EU has also followed Venezuela's preferences, which have been less geared towards democratic reforms (especially in the partial regimes). Together with the limited interest and agenda of Spain as the dominant EU actor in democracy promotion towards Latin America (i.e. the institutional hypothesis), this explains why domestic deficiencies in Venezuela have generally been under-addressed. Eritrea is another case where the EU has largely followed the government's preferences, even if this means that domestic deficiencies are severely under-addressed. What determines the EU's substance in this case (also in comparison to Ethiopia) is not so much the 'objective' democratic situation, but rather the reluctance of the government to accept external intervention to support democracy and the EU's readiness to adjust its agenda accordingly (Chapter 14).

Thus, while our contributors found some evidence for the adaption of the substance of democracy promotion to the domestic context in terms of governments' preferences, in no case did the EU leave the definition of substance exclusively to the third country. Still, there are differences in the degree to which the EU accepts ownership in democracy promotion. At one end of the spectrum, there are the candidate countries that do not have much leeway in defining which substance of democracy is being promoted. As the case of Turkey shows, their governments can only influence the substance on the implementation side, that is, by 


\section{PROOF}

Anne Wetzel and Jan Orbie 249

refusing to transpose certain parts of the agenda. At the other end, in its development policy the EU adheres to agreements such as the 2005 Paris Declaration on Aid Effectiveness that remind donors to take ownership seriously. This is clearly reflected in the regulation on the European Development Fund (EDF) and, eventually, in the profile of EDF-funded assistance (see also Del Biondo forthcoming 2015). As mentioned above, the application of ownership principles often reinforces the EU's outputoriented tendency. In theoretical terms, this variation shows how the domestic context interrelates with institutional factors.

Another finding from a range of case studies is that despite its acknowledgement of domestic particularities, the EU does not engage with democratic concepts that emerge in third countries' domestic contexts. Be it 'revolutionary democracy' in Ethiopia (Chapter 14), or the model of democracy related to the Bolivarian revolution in Venezuela (Chapter 16), the EU does not take up and get involved in such discourses. Only in Russia has the EU tried to connect the promotion of functioning administration and of corruption to the discourse on 'modernization', without, however, discussing it further or even elaborating on the prevailing notion of 'sovereign democracy' (Chapter 9).

Institutional factors have not emerged as of major explanatory value. It is clear that different member states and sub-systems within the EU hold different templates of what democracy promotion should entail (see e.g. Ribeiro-Hoffmann in Chapter 16 on Spain, but also the difference between the Commission, the Council and the European Parliament, and Stewart in Chapter 9 on Poland). Some chapters have also confirmed that EU actors and institutions with a developmental background rather favour a shallow democracy promotion agenda (see e.g. Chapter 15 on the inter-institutional quarrels between Directorate General (DG) Development and DG Relex on whether the EDF should be used for poverty reduction or electoral assistance). Here, the interrelatedness between institutional factors and attention to the third country government's agenda also comes into play (see above). Furthermore, the case of the European Parliament's complaint about the limited attention paid to socio-economic development in the Commission's draft Country Strategy Paper on Brazil shows that the legal basis of the financial source is important for the content of the policy. Since in this case the funding was based on rules that relate to development co-operation, the Parliament argued that the Commission had to follow the respective (development) priorities instead of others (see Chapter 16). As Kochenov underlines in his contribution, the absence of certain legal rules related to democracy from the EU's acquis is a characteristic of EU democracy promotion (Chapter 2). This becomes evident 


\section{Comparison and Conclusion}

with regard to the component of 'stateness', which has generally not been overly important in EU democracy promotion. One of the reasons that has been identified in the literature is the lack of respective rules in this sphere (Bieber 2011: 1793). This shows that institutional factors also reflect and further reinforce the more fundamental 'nature of the beast' explanation. Related to this is the characteristic role of the European Commission in the EU system of governance that can be said to contribute to the EU as a rather output-oriented political construction, as argued above. That EU external relations have, to a large extent, been driven by the Commission partly explains its outputoriented character, as argued by Reynaert in relation to Tunisia and Egypt (Chapter 11). Interestingly, this reasoning implies that the EU may take a broader approach to democracy promotion when the European External Action Service (EEAS) becomes more closely involved, as found by Del Biondo in relation to Ethiopia and Eritrea (Chapter 14). In a similar vein, one might also hypothesize that the growing role of the European Parliament would broaden the EU's democracy promotion agenda, as has been suggested in several chapters (e.g. Chapter 9 on Russia and Ukraine, Chapter 16 on Brazil and Venezuela, and Chapter 15 on Fiji and Solomon Islands).

However, these generalizations remain speculative. While the diversity of substances within the EU has been recognized throughout this volume, overall the chapters have not provided much evidence that the institutional factor is a decisive one. Furthermore, many chapters show that the same institutional configuration towards two countries (e.g. Kazakhstan and Kyrgyzstan; Ethiopia and Eritrea; Brazil and Venezuela) can still lead to diverse findings on the substance.

Three closely related reasons for the limited specific explanatory value of the institutional hypothesis come to mind. First, within the EU there are few cases where one member state and/or one sub-system is dominant. European foreign policy usually involves a compromise and/or coexistence of various policies. Arguably, this is even more true in a 'horizontal' domain such as democracy promotion, which is (in contrast to trade, aid, climate change, etc.) not confined to a (mainly) single institutional sub-system. This diversity of models is precisely why some authors, such as Kurki and De Ridder, talk about the 'fuzziness' or 'vagueness' (Chapters 3 and 6, respectively) of the EU's substance. Second, in the few cases where dominant member states or sub-systems can be identified, these tend to be the ones that are less interested in democracy promotion. This has been shown in the cases of Brazil/Venezuela (Chapter 16), Israel/Palestine (Chapter 12) and Russia 
(Chapter 9). In each of these cases, the limited attention to democracy issues by key actors has gone hand in hand with a shallow or a superficial agenda. Third, other factors such as the EU's power relationship with third countries, the domestic context on the recipient side, and of course the EU's 'default' output-oriented tendencies, are generally more important than the intra-EU institutional configuration. All this does not imply that the institutional dimension is irrelevant, but rather that it is closely connected with, and often subordinate to, other factors.

Apart from the above explanations, there may be a methodological reason for why the institutional hypothesis seems to be less important. Opening the black box of EU institutions proves difficult and demands intense fieldwork. For instance, it was pointed out that it is difficult to trace individual member states' influence in the Council because its meetings take place behind closed doors (Chapter 13). Thus, while we do not think that intensified studies would change the general picture, they could still provide important further insights with regard to different understandings of democracy (promotion) in different DGs, the translation of paradigms into action, scope conditions under which institutional factors matter and the interaction of institutional factors with others.

Similar to the situation regarding institutions, inter-organizational context does not emerge as a decisive factor. This resonates with the observation that 'there is a lack of global coordination among developed countries supporting democracy promotion throughout the world' (Epstein et al. 2007: 22). Usually, each democracy promoter pursues its own democratization agenda (Burnell 2008: 416, Merkel 2010: 154-59). Still, there are instances where the EU's substance of democracy promotion is shaped in coordination with other actors, or at least with a view to other actor's activities. Some cases have already been mentioned above. With regard to elections, more generally, the OSCE is mentioned in several chapters as an important actor that has limited the role of the EU. The same is true for specific EU member states and other states. As Del Biondo argues, the involvement of the UK and the US in security sector reform in Ethiopia has reduced the need for EU involvement in this field (Chapter 14). On the other hand, the same chapter shows that initiatives conducted by other actors may attract EU financial support. Given that staff and expertise are valuable resources that the EU does not always have, supporting joint projects such as the World Bankadministered Public Sector Capacity-Building Programme in Ethiopia seems to be an alternative. Similar to the case of Fiji mentioned above, in the case of Israel and Palestine the EU's activities take place in an 


\section{PROOF}

environment that is dominated by another external actor (here the US), which has an impact on the EU's policy.

This makes it clear that further research should explore not only the relative explanatory value of different factors, but also how they interrelate and correspond to different strata or layers of explanation. As argued within critical realist scholarship, research constitutes a neverending search for ever more accurate explanations beyond observable events. This implies that diverse theories and explanations can be integrated into a multi-causal analysis, whereby some work at deeper levels than others (Kurki 2008, Bailey 2009). In our case, the 'nature of the beast' seems the most fundamental explanation (see also Wetzel et al.

AQ2 forthcoming 2015), whereas the other factors play a role in a number of ways that deserve further study.

\section{Conclusions}

The main objective of this book was to map and explain the substance of EU democracy promotion. Briefly summarized, this concluding chapter has found that the 'default substance' or 'basso continuo' of the EU's democracy promotion is output-oriented, specifically targeting 'socioeconomic development' and 'state administrative capacity'. At the same time, the EU has, in most cases, and in particular in recent candidate countries, addressed at least some of the partial regimes that lie at the core of the definition of embedded liberal democracy. This finding helps to shed light on the puzzle outlined in the introductory chapter. While EU democracy promotion generally includes key elements of liberal democracy, we detect a focus and the closest match with existing 'deficiencies' in third countries with regard to 'output-oriented' components that belong to the context conditions instead of the definitional core of embedded liberal democracy.

Looking for explanations, the 'nature of the beast' seems the most AQ3 fundamental factor (see also Wetzel et al. forthcoming 2015), while feasibility concerns, power relations and domestic context conditions are also important. The institutional and inter-organizational hypotheses appear to have less immediate explanatory value, although it should be mentioned that all explanations are interrelated in complex ways.

Further research could elaborate these findings by extending the mapping as well as specifying the explanations. In order to do so, both carefully designed case studies and quantitative, statistical analyses should be considered. Although this volume addresses a large number of third countries spanning around the globe, there is room for 
further comparative analysis. In the process of the editing of this book, it has proven particularly difficult to find researchers working on EU democracy promotion in Asia and Latin America. Whereas the EU's broader normative agenda, including human rights, has been studied extensively, the literature on EU democracy promotion largely focuses on Africa and on the European neighbourhood. The reason for this may be that academics and policy-makers consider other concerns to be more pressing and more relevant, whereas democracy promotion is either unnecessary because countries are already democratized to a large extent (e.g. in Latin America) or unfeasible because it faces strong opposition from the government (e.g. in China). However, these assumptions can be seriously questioned. As Ribeiro-Hoffmann rightly argues in Chapter 16, a wider view on democracy allows identifying different, previously unexplored dimension in the EU's relations with Latin America. It would also be a shame if China continues to be neglected in further research, not only because it is 'the de facto leader of those countries that are resisting the global advance of democracy' but especially because its authoritarian rule may not endure alongside economic openness (Nathan et al. 2013: 6). A broader, 'embedded liberalism' perspective could be particularly fruitful in this regard, since it allows for not only capturing the potential richness of democracy, but also the various ways through which it could be promoted. Carefully selected additional case studies could help advance our knowledge about the substance of (EU) democracy promotion by controlling for particular variables or by detailed process tracing.

Beyond case studies, there is also room for advancement with regard to quantitative methods. With the BTI there exists a dataset that includes a large number of countries, that is updated every two years and that breaks down the notion of democracy into single components which are measured individually. It would therefore be conceivable to extend the mapping exercise to more countries (see above) and use statistical methods to learn about the match or mismatch between the promoted substance and the existing deficiencies on a larger scale.

When it comes to explanations, further theorizing on the different hypotheses would be desirable, for example by conceiving of different 'layers' of explanations and how they interrelate. Our findings indicate that the 'nature of the beast' plays at a more fundamental level, which may also be the case for institutions and inter-organizational context. While the latter two did not display strong explanatory power at a specific level across our cases, their relevance could be studied further with a view to underlying attitudes. With regard to institutions, 


\section{PROOF}

in particular, such a perspective could be applied in a detailed study of attitudes towards democracy promotion held by the EU policymakers, which may relate back to the 'nature of the beast' explanation. It should also be kept in mind that the importance of a factor such as inter-organizational field may vary over time and in view of changing paradigms and patterns of donor coordination. Such changes may be subject to further study themselves. Feasibility concerns, power relations and domestic context conditions seem to operate at an intermediate level, and further research could aim to identify scope conditions under which these hypotheses apply or build chains of explanations that include these factors as independent and intervening variables. Thus, future research should engage in more intricate analysis of the different explanations for the substance of EU democracy promotion, thereby also identifying the conditions under which the substance might change.

\section{Notes}

1. Values for Fiji and the Solomon Islands were constructed from the scores given in the respective country chapter. We opted for the 2006 BTI values as a reference because many Country Strategy Papers (CSPs) and the respective Indicative Programmes that the authors refer to relate to the time frame of 2007-2013. These documents were drawn up at the beginning of the 20072013 programming period. Thus, if the domestic context has played a role in drafting the CSPs and related documents and eventually in designing the substance of democracy promotion, the situation shortly before the start of this funding period, which is reflected in the 2006 BTI values, should have been relevant for the policy-makers.

2. With regard to socio-economic development, it can be argued that the scores are a modest judgment given the fact that we did not include the EU measures aimed at the development of a functioning market economy, which the $\mathrm{EU}$ deems to contribute to the (output-related) improvement of the socio-economic situation in third countries. Thus, including market-building activities (cf. the Chapter by Kurki) would justify the characterization as output-related even more.

3. 'Electoralist fallacy' refers to an exclusive focus on and over-evaluation of elections for successful democratization (see for instance Schneider and Schmitter 2004: 88, Endnote 14).

4. With Ethiopia and Venezuela rated as partly free and Russia, Egypt and Eritrea rated as not free: http://www.freedomhouse.org/report/freedom-world/ freedom-world-2006\#tabs-0-bottom-2.

5. Apart from the lack of such discussion in the EU documents, the issue was not raised in various discussions we had with the EU officials (Brussels, 2 July 2012; see www.eu-ipods.eu). 


\section{PROOF}

QUERIES TO BE ANSWERED BY AUTHOR (SEE MARGINAL MARKS)

IMPORTANT NOTE: Please mark your corrections and answer to these queries directly onto the proof at the relevant place. Do NOT mark your corrections on this query sheet.

Chapter 17

\begin{tabular}{lll}
\hline Query No. & Page No. & Query \\
\hline AQ1 & 249 & Please update - forthcoming \\
AQ2 & 252 & Please update - forthcoming \\
AQ3 & 252 & Please update - forthcoming \\
\hline
\end{tabular}

